\title{
DNA end-independent activation of DNA-PK mediated via association with the DNA-binding protein C1D
}

\author{
Ugur Yavuzer, ${ }^{1,3}$ Grame C.M. Smith, ${ }^{1}$ Tonya Bliss, $^{1}$ Dieter Werner, ${ }^{2}$ and Stephen P. Jackson ${ }^{1,4}$ \\ ${ }^{1}$ Wellcome Trust/Cancer Research Campaign Institute of Cancer and Developmental Biology and Department of Zoology, \\ Cambridge University, Cambridge CB2 1QR, UK; ' ${ }^{2}$ Division Biochemistry of the Cell, German Cancer Research Centre, \\ D-69009 Heidel berg, Germany
}

\begin{abstract}
DNA-dependent protein kinase (DNA-PK), which is involved in DNA double-strand break repair and V (D)J recombination, is comprised of a DNA-targeting component termed Ku and an $\sim 465-k D$ catalytic subunit, DNA-PK ${ }_{c s}$. Although DNA-PK phosphorylates proteins in the presence of DSBs or other discontinuities in the DNA double helix in vitro, the possibility exists that it is also activated in other circumstances via its association with additional proteins. Here, through use of the yeast two-hybrid screen, we discover that the recently identified high affinity DNA binding protein C1D interacts with the putative leucine zipper region of DNA-PK ${ }_{\mathrm{cs}}$. Furthermore, we show that C1D can interact with DNA-PK in mammalian cells and that CID is a very effective DNA-PK substrate in vitro. Final ly, we establish that C1D directs the activation of DNA-PK in a manner that does not require DNA temini. Therefore, these studies provide a function for CID and suggest novel mechanisms for DNA-PK activation in vivo.
\end{abstract}

[Key Words: DNA-PK; DNA repair; recombination; C1D; nuclear matrix]

Received December 5, 1997; revised version accepted M ay 22, 1998.

The DN A double-strand break (DSB) is one of the most dangerous and potentially lethal lesions that can occur within the cell. DNA DSBs can arise when DNA replication compl exes encounter damage or secondary structures in the DNA template, by free radical damage as a consequence of oxidative metabolism, or are induced by ionizing radiation (IR) or radiomimetic chemicals. DN A DSBs are also generated as intermediate structures during $\mathrm{V}(\mathrm{D})$ J recombination, which mediates the rearrangement of immunoglobul in and T-cell receptor genes (for review, see Alt et al. 1992; Gellert 1992). Therefore, DSB repair is not only critical for maintaining genomic integrity but is also essential for the normal development of the immune system.

Genetic and biochemical complementation studies have revealed that $D S B$ repair and $V(D)$ J recombination are reliant on the DNA-dependent protein kinase (DNAPK). DNA-PK is an abundant nuclear protein serine/ threonine kinase that is activated in vitro by DNA DSBS and certain other perturbations in the DN A double helix (for review, see Anderson and Lees-Miller 1992; Jackson 1997; Smith et al. 1998). Biochemical studies have revealed that DNA-PK is a multiprotein complex consist-

\footnotetext{
${ }^{3}$ Present address: Bilkent University, Molecular Biology Department, Ankara, Turkey

${ }^{4}$ Corresponding author.

E-MAIL spj13@molebio.cam.ac.uk; FAX (01233) 334089.
}

ing of a 465-kD catalytic subunit termed DN A-PK $c$ and a DNA-binding component called $\mathrm{Ku}$, which is composed of two tightly associated polypeptides of $\sim 70$ and 80 kD (Ku70 and Ku80, respectively; Dvir et al. 1993; Gottlieb and Jackson 1993). DN A-PK has been shown to phosphorylate a variety of proteins in vitro, including H sp90, Sp1, SV40 T antigen, p53, serum response factor (SRF), c-Fos, c-Jun, and the carboxy-terminal domain of RNA polymerase II (Anderson and Lees-Miller 1992; Jackson 1997). Although $\mathrm{Ku}$ helps to recruit DNA-PK to DNA in vitro and is thus likely to be required for the physiological activation of DNA-PK at sites of DNA damage, there is evidence that, at least in vitro, DNA$\mathrm{PK}_{\mathrm{cs}}$ can bind to DNA and exhibit kinase activity in the absence of Ku (Y aneva et al. 1997; Hammarsten and Chu 1998). The activation of DN A-PK by DN A DSBs suggests that it may function in vivo by recognizing recombination intermediates and/or DNA ends at sites of DNA damage. Defects in DNA-PK components cause radiosensitivity and an inability to perform $V(D)$ J recombination (for review, see Jackson and Jeggo 1995; Jackson 1996; Lieber et al. 1997).

The biochemical characteristics of DNA-PK have led to several hypotheses regarding its function in vivo (Jackson and Jeggo 1995; Roth et al. 1995 and references therein). For example, it has been suggested that DNAPK may align the broken DNA ends or interact directly with other components of the DN A repair machinery to 
target them to sites of DNA damage. Alternatively, or in addition, DNA-PK might function by modifying the activity of DNA repai r factors by phosphorylation. It could also counteract the action of transcription factors or chromatin, which might otherwise interfere with the assembly of the DNA repair complex. Finally, and consistent with the fact that DNA-PK $c$ is related to several factors involved in DNA damage-induced cell cycle checkpoint control processes (Hartley et al. 1995; Keith and Schreiber 1995; Jackson 1997), DN A-PK activation could trigger DN A damage signaling cascades that ultimately impinge on the transcription, DNA replication, cell cycle, and/or apoptotic machineries.

Despite the substantial progress achieved in recent years in our understanding of DNA-PK, a number of issues concerning its physiological functions and mechanism of action remain outstanding. For example, although several proteins have been found to act as DN APK substrates in vitro, factors phosphorylated by DNAPK in vivo have yet to be defined unequivocally. Clearly, the identification of physiological targets for DNA-PK would greatly facilitate investigations into the mechanisms and consequences of DNA-PK activation. In addition, it remains to be established whether there are situations in vivo in which DNA-PK activation does not invol ve free DN A ends and, if so, whether this is brought about by DNA-PK associating with additional proteins. Regarding this point, it should be noted that DNA-PK is present at $\sim 1 \times 10^{5}$ to $5 \times 10^{5}$ molecules per human cell, which is far in excess of the number of DNA DSBs generated by physiological doses of DNA damaging agents. Although one explanation for this is that large quantities of DN A-PK are required to al low the rapid detection and repair of DNA damage, an alternative model is that DNA-PK may have functions in addition to its roles in DNA DSB repair. A final crucial issue is that all assays for DNA-PK have so far employed naked DNA templates, whereas it is clear that DNA is complexed with histones and various nonhistone proteins in vivo. The question thus arises as to whether such chromatin components exert positive or negative influences on DNAPK activation. Notably, in this regard the chromatinassociated high mobility group (HMG) proteins 1 and 2 have been shown to stimulate DN A-PK activity in vitro (Watanabe et al. 1994) and recent investigations have established that certain proteins required for heterochromatin-mediated gene silencing in yeast interact with $\mathrm{Ku}$ and are required for effective DNA DSB repair (Tsukamoto et al. 1997; Boulton and Jackson 1998).

As an approach to address some of the above issues, we have applied the yeast two-hybrid system (Fields and Song 1989) to screen for polypeptides that interact with

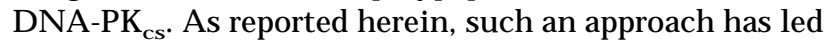
us to identify a novel protein, C1D, which interacts specifically with the potential leucine zipper $(L Z)$ region of DNA-PK ${ }_{\mathrm{cs}}$ both in vitro and in vivo. We also show that C1D is a very efficient substrate for DNA-PK in vitro. Moreover, unlike most other DNA-PK substrates identified so far, which are phosphorylated by DNA-PK only in the presence of linear DNA, CID can activate DNA-
PK in the presence of a supercoiled plasmid DNA molecule. The potential implications of these results in regard to the biological roles of C1D and DNA-PK in DN A repair, V(D)J recombination, and other processes are discussed.

\section{Results}

Identification of proteins interacting with the putative $\mathrm{LZ}$ region of DNA-PK

The cloning of the cDNA for human DNA-PK ${ }_{c s}$ has revealed that it encodes a protein of $\sim 465 \mathrm{kD}$ that possesses a phosphatidylinositol 3-kinase (PIK) catalytic domain toward its carboxyl terminus (Hartley et al. 1995). Other than this, the only other significant feature that has been noted previously for the DN A-PK ${ }_{c s}$ polypeptide is the presence of a potential LZ motif encompassing residues 1503-1538 (Fig. 1A). Because some LZs have well-documented roles in mediating protein-protein interactions, we decided to see whether we could identify factors that interact with this regi on of DNA-PK ${ }_{\mathrm{cs}}$ by the yeast two-hybrid screen approach. To this end, we generated the yeast expression plasmid pLexA-LZ ${ }_{c S}$, which di rects the synthesis of residues 1501-1602 of DNA-PK fused to the carboxy-terminal DNA-binding domain of the bacterial LexA protein (this fusion is referred to as $\mathrm{pLexA}-\mathrm{L} Z_{\mathrm{cs}}$ ). pLexA-LZ $Z_{\mathrm{cs}}$ was then introduced into the yeast reporter strain L40 (Hollenberg et al. 1995) that contains both the HIS3 and lacZ genes under the control of LexA operators. Importantly, L40 containing pLexA$\mathrm{LZ}_{\mathrm{cs}}$ is $\mathrm{His}^{-}$and expresses no detectable $\beta$-gal actosidase activity, indicating that the $L Z$ region of DNA-PK $c$ is transcriptionally inert when fused to LexA.

Strain $L 40$ containing pLexA-LZ $Z_{c s}$ was transformed with a human B-lymphocyte cDN A library in the vector pACT. A total of $\sim 1 \times 10^{6}$ transformants were obtained, of which, $\sim 1 \times 10^{3}$ were capable of growing on medium lacking histidine. Of these, 300 were found to produce elevated $\beta$-galactosidase activity. After elimination of false positives by use of other LexA fusion proteins (linked to the proteins Lamin and Daughterless) as baits, 100 transformants were identified as containing cDN As that conferred a $\mathrm{His}^{+}, \mathrm{LacZ}^{+}$phenotype in a fashion that was specific to $L 40$ cells expressing the LexA-DN A-PK fusion protein. The cDN A expression vectors from 20 of these transformants were then rescued, and sequencing revealed that 17 contained overlapping sequences derived from the same cDNA. A search of the GenBank database reveal ed that this CDN A corresponds to that of a 16-kD polypeptide, termed C1D (GenBank accession no. X95592). CID is a ubiquitously expressed nuclear protein that has been identified recently by screening a cDNA expression library with monoclonal antibodies raised against the residual polypeptides that remain attached to DNA even following aggressive purification methods that employ SDS, proteinase K, and phenol extraction (N ehls et al. 1998; U. Y avuzer and S.P. Jackson, unpubl.; also see Discussion). N otably, the amino acid sequence of C1D does not reveal significant homologies 
$\mathbf{A}$

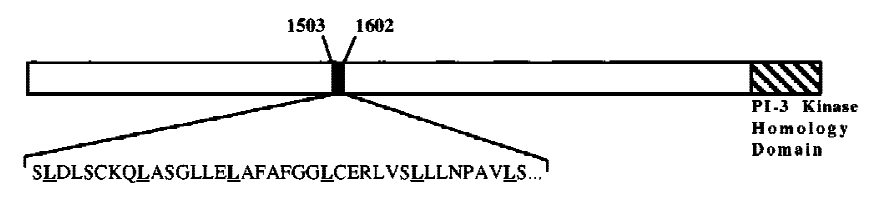

Mut1LZcs: SLDLSCKQPASGLLELAFAFGGLCERLVSLLLNPAVLS...

Mut2LZes: SLDLSCKQLASGLLDPAFAFGGLCERLVSLLLNPAVLS...

Figure 1. C1D interacts with the $L Z$ region of DNA-PK ${ }_{c s}$. (A) Schematic diagram of DNA$\mathrm{PK}_{\mathrm{cs}}$. The kinase domain (hatched box) and the $L Z$ region used as a bait in the yeast two-hybrid system are indicated. Mutations introduced into the LZ motif to produce constructs, Mut $1 L Z_{c s}$ and $M$ ut2L $Z_{c s}$, are indicated by asterisks, and the leucine residues of the motif are underlined. (B) C1D fused to VP16 activation domain (Prey) was transformed into L40 strain together with LexA-LZ ${ }_{c S}$ LexA, or other LexA fusion proteins (Lamin and Daughterless). Interactions were measured by $\beta$-gal actosi dase activity. (C) C1D fused to the carboxy-terminal DNA-binding region of LexA (Bait), and the $\mathrm{LZ}_{\mathrm{cs}}$ was fused to the VP16 activation domain. (D) M utations that disrupt the LZ motif abolish the DNA-PK ${ }_{\mathrm{cs}}-\mathrm{C}$ ID two-hybrid interaction.
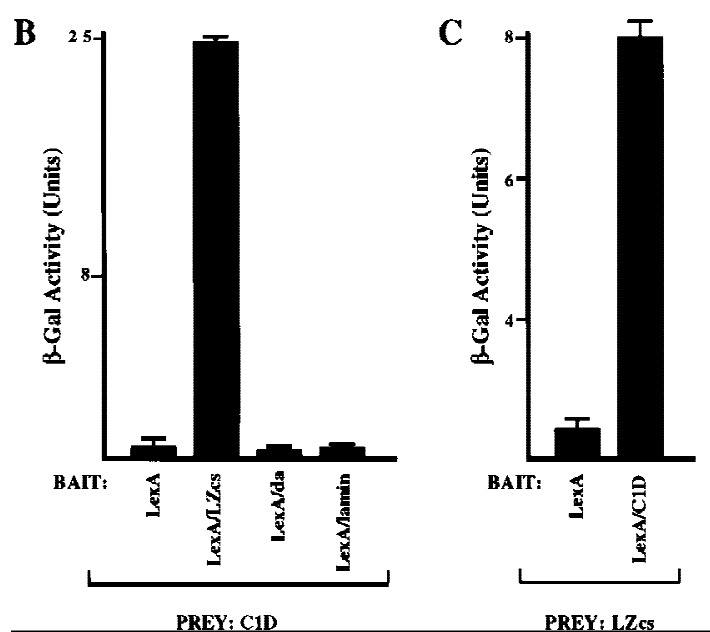

with any known functional protein domains nor to previously characterized proteins.

$C 1 D$ interacts with the putative $L Z$ region of DNA-PK ${ }_{\mathrm{cs}}$ specifically

To establish the specificity of the two-hybrid interaction between CID and the LZ region of DNA-PK ${ }_{\mathrm{CS}}$, the rescued CID CDNA clone was transformed into L40 together with baits comprising the LexA DNA-binding domain alone, LexA-LZ $Z_{c s}$, LexA-Daughterless, or LexALamin, and the level of activity from the integrated IacZ reporter was determined in each case. As shown in Figure $1 B, C 1 D$ interacts with LexA-LZ $Z_{c s}$ very strongly but not with LexA alone, LexA-Daughterless, nor LexA-Lamin. To confirm the specificity of the C1D-DNA-PK interaction further, we performed the two-hybrid experiment in reverse. Thus, C1D was fused to the carboxyterminal DN A-binding region of LexA, and the region of DNA-PK ${ }_{c s}$ containing the LZ was fused to the VP16 activation domain. Significantly, the introduction of plasmids expressing these two proteins into strain $L 40$ results in significant $\beta$-galactosidase activity (Fig. 1C), whereas only background $\beta$-galactosidase activity is detected when LexA alone is tested for a two-hybrid interaction with VP16-LZ $Z_{c s}$. Therefore, CID and the region encompassing the putative LZ motif of DNA-PK ${ }_{c s}$ can interact irrespective of which acts as bait.

Because the region of DNA-PK studies comprises $\sim 100$ amino acid residues and extends beyond the putative LZ motif, we wished to determine whether this motif is required for the interaction with C1D. To this end, two specific mutations were intro- duced into the LZ motif, and the ability of each of these mutated derivatives to interact with C1D in the twohybrid assay was compared with that of the wild-type polypeptide. In one mutant, termed mut $1 \mathrm{LZ} Z_{\mathrm{cs}}$, the second leucine residue within the $L Z$ motif is mutated to a proline residue, whereas in the second mutant, mut $2 \mathrm{~L} Z_{\mathrm{cs}}$, the third leucine and preceding glutamic acid residue are mutated to prol ine and aspartic acid residues, respectively (Fig. 1A). N otably, as shown in Figure 1D, although CID interacts efficiently with the wild-type DNA-PK ${ }_{c s}$ derivative, no significant interaction is detected for each of the specific point mutations affecting the integrity of the LZ motif. These data therefore reveal that the two-hybrid interaction between DNA-PK ${ }_{c s}$ and CID requires an intact DN A-PK $\mathrm{CSZ}_{\mathrm{CS}}$ motif and suggest strongly that this region mediates, at least in part, the interaction between these two factors.

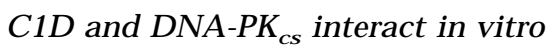

N ext, we wanted to determine whether C1D is able to bind to DNA-PK ${ }_{c s}$ in vitro. To this end, C1D was expressed in Escherichia coli as a fusion to GST, was purified by use of glutathione-agarose beads, and the immobilized GST-C ID fusion protein was then incubated with a protein fraction containing the DNA-PK holoenzyme. After extensive washing of the beads, the proteins bound to GST-CID were resolved by SDS-PAGE followed by Western blotting and probing with an antibody specific for DN A-PK ${ }_{\mathrm{cs}}$. As shown in Figure 2A, al though no interaction is observed between DNA-PK ${ }_{\mathrm{cs}}$ and GST alone, a substantial proportion ( $10 \%)$ of the input DNA$\mathrm{PK}_{\mathrm{Cs}}$ is bound by GST-C ID. In contrast, when a control 
A

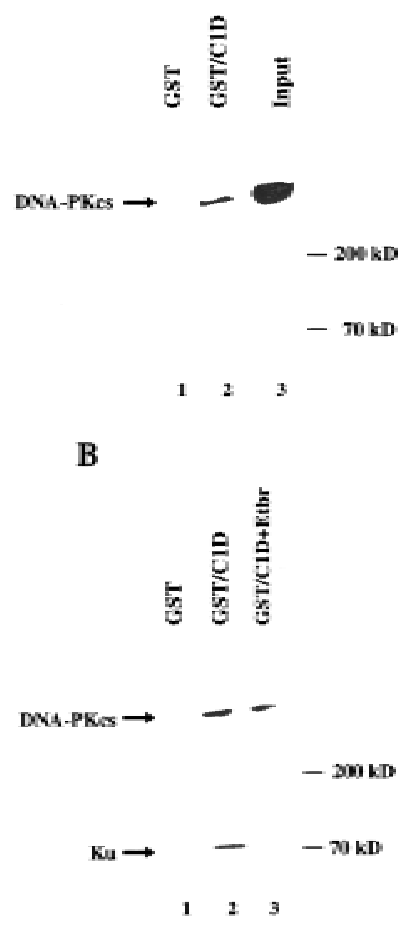

Figure 2. $C 1 D$ and $D N A-P K_{c s}$ interact in vitro. (A) GST or GST-C1D (0.5 $\mu \mathrm{g}$ in each case) was incubated with $5 \mu \mathrm{g}$ of purified DNA-PK and subjected to GST pull-down assays, and Western blots were performed with a DNA-PK ${ }_{c s}$ antibody. Quantitation reveals that $\sim 10 \%$ of DNA-PK ${ }_{\mathrm{cs}}$ binds to GSTC1D in this experiment, suggestive of a $1: 1$ binding ratio. (B) GST pull-downs were performed as in A (for lane 3, the pulldown reaction included ethidium bromide), then proteins were immunoblotted with antibodies against Ku or DNA-PK ${ }_{\mathrm{cs}}$.

protein was employed consisting of a fusion of GST to the protein CBP, no interaction with DNA-PK ${ }_{\mathrm{cs}}$ was apparent (data not shown). Because the DNA-PK ${ }_{c s}$ preparation used for the above assays also contained $\mathrm{Ku}$, we were prompted to ascertain whether C1D binds DNA$\mathrm{PK}_{\mathrm{cs}}$ al one or whether it can interact with the Ku-DNA$\mathrm{PK}_{\mathrm{cs}}$ complex. In addition, because both C ID and Ku can bind to DN A, it was important to see whether the interaction detected was di rect or was mediated indirectly via DNA that might have contaminated either the GSTC1D or DNA-PK samples. To address these issues, we used ethidium bromide, which disrupts protein-DNA interactions by intercal ating into the DNA double helix (Lai and Herr 1992). Thus, GST-CID was tested for interactions with DNA-PK $c$ and $\mathrm{Ku}$ in the presence or absence of ethidium bromide. Significantly, these studies revealed that whereas both DN A-PK ${ }_{c s}$ and $\mathrm{Ku}$ bind to the GST -C ID beads in the absence of ethidium bromide, in the presence of ethidium bromide, only DNA-PK $\mathrm{Cs}_{\mathrm{cs}}$ is retained (Fig. 2B). Taken together, these data indicate

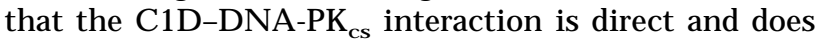
not appear to be mediated by or require a DN A cofactor. In contrast, C1D does not interact with Ku directly, al- though these factors can associate indirectly in the presence of DNA, presumably via their interactions with DNA-PK ${ }_{c s}$. Consistent with this, no interaction is observed between C1D and $\mathrm{Ku}$ in the absence of ethidium bromide in reactions that lack DNA-PK ${ }_{c s}$ (data not shown). Finally, these results suggest strongly that DNA-PK ${ }_{c s}$ is able to contact both CID and Ku simultaneously.

\section{C1D is an efficient substrate for DNA-PK in vitro}

The interaction between DNA-PK ${ }_{c s}$ and C ID suggested that C1D might represent a substrate for DNA-PK and/ or might regulate DNA-PK activity. To address these issues, we expressed full-length CID in E. coli as a Histagged fusion protein. N otably, this protein on its own is highly insoluble under nondenaturing conditions, but can be obtained in soluble form by denaturing it with 8 $\mathrm{M}$ urea and then gradually refolding the protein by withdrawing the urea by dialysis in the presence of either linear or supercoiled plasmid DNA. Such a procedure results in soluble DNA-bound CID (if DNA is not present in the dialysis procedure, essentially all C1D becomes insoluble; D. Werner and U. Yavuzer, unpubl.). Recombinant C1D purified and refolded by this method was recognized by rabbit polyclonal sera raised against either the His-tagged C1D or a GST-C ID fusion protein (see $M$ aterial s and $M$ ethods). To determi ne whether C ID can serve as a substrate for DNA-PK, we incubated the His-tagged CID that had been assembled onto a linear plasmid molecule with DN A-PK (comprising DNA-PK and $\mathrm{Ku}$ ) in the presence of $\left[\gamma^{32} \mathrm{P}\right]-\mathrm{ATP}$. These studies reveal ed that CID is recognized very effectively as a DN APK substrate, with phosphorylation being of similar efficiency to the well-characterized DN A-PK substrate p53 (Fig. 3A, lanes 3,4). However, the GST-C ID fusion protein was not recognized as a substrate, presumably because of the target site(s) on C1D being obscured.

C1D activates DNA-PK in the presence of supercoiled plasmid DNA

Previous studies have established that DNA-PK interacts with DN A ends and, therefore, is activated strongly by linear DNA but only weakly, if at all, by closed-circular plasmid DN A (Gottlieb and Jackson 1993; Suwa et al. 1994). In the course of our investigations into C ID phosphorylation by DNA-PK, we made the surprising observation that C ID assembled onto a supercoiled plasmid DN A (pKTMLP) al so serves as a very effective DNAPK substrate (Fig. 3B, lane 4). Furthermore, the inclusion of free supercoiled plasmid DNA does not result in an increase in C1D phosphorylation (Fig. 3B, lane 3). The phosphorylation of C1D is dependent on the presence of the DNA-PK preparation, because no C1D phosphorylation is obtained either with C1D alone or with C1D together with free plasmid DNA (Fig. 3B, lanes 1 and 7, respectively).

Although the above studies utilized highly purified DNA-PK, the possibility existed that CID might be be 


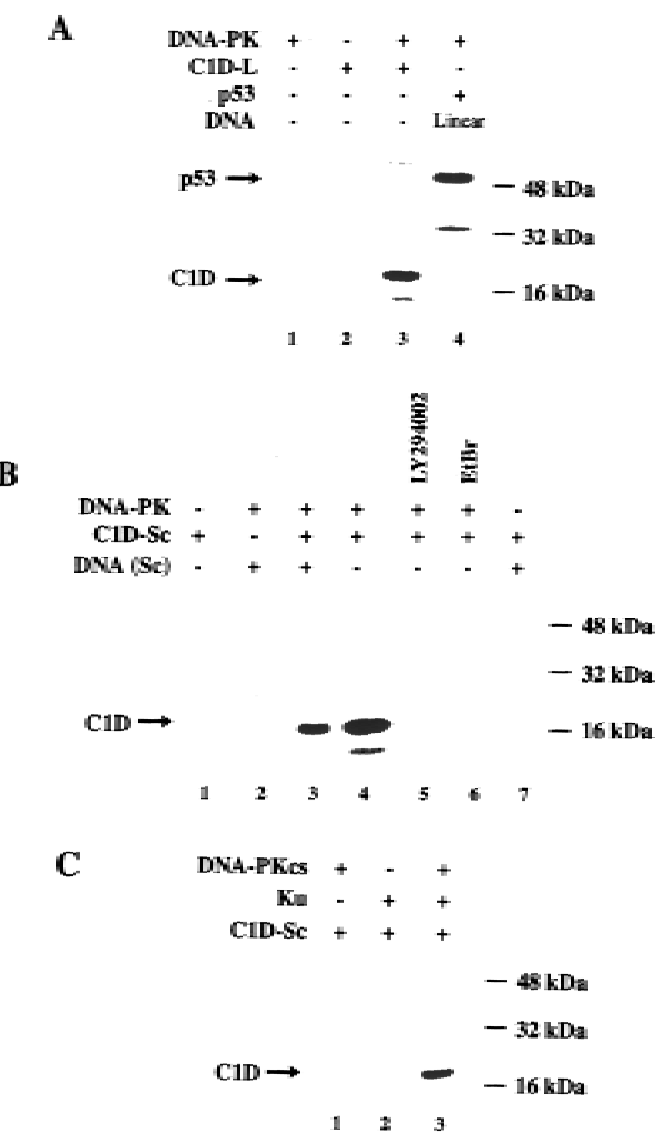

Figure 3. $C 1 D$ is a strong substrate for DNA-PK in vitro. (A) C1D refolded on a linear plasmid (C1D-L) or p53 was incubated with purified DNA-PK, and in vitro kinase assays were performed as described in M aterials and M ethods. Linear DN A was added to the reaction for lane 4. (B) C1D refolded on supercoiled plasmid (C1D-Sc) was incubated with purified DNA-PK as described above. Where indicated, ethidium bromide or LY 294002 were incubated with proteins for $30 \mathrm{~min}$ before starting the kinase reaction. (C) As indicated, highly purified DNA-PK and/or Ku was incubated with C1D-Sc and kinase assays were performed.

ing phosphorylated not by DNA-PK but by a contaminating kinase in the DNA-PK preparation. To address this issue, we took advantage of the fact that the fungal metabolite wortmannin and the synthetic agent LY 294002 have been shown to be potent inhibitors of DNA-PK but do not affect most characterized protein Ser/Thr kinases (G. Smith, N. Lakin, and S.P. Jackson, unpubl.). Significantly, the phosphorylation of C1D by DN A-PK preparations is abolished by the addition of either wortmannin (data not shown) or LY 294002 (Fig. 3B, lane 5). In addition, phosphorylation is abrogated in the presence of ethidium bromide (Fig. 3B, lane 6). These data therefore provide strong support that the active C1D kinase is DNA-PK. Given that C1D interacts directly with DNA-PK ${ }_{c s}$ but not $\mathrm{Ku}$, we asked whether CID could be phosphorylated by DNA-PK ${ }_{c s}$ in the absence of $\mathrm{Ku}$. As seen in Figure $3 \mathrm{C}$, no phosphorylation of CID is observed in the presence of DNA-PK ${ }_{c s}$ or $\mathrm{Ku}$ alone, and phosphorylation is detected only when both proteins are present concurrently. Taken together, these data reveal that al though C1D phosphorylation by DN APK is DN A dependent, it differs from other well-characterized DNA-PK-mediated phosphorylation events in that it can be promoted by supercoiled plasmid DNA (also, see below). N evertheless, $\mathrm{Ku}$ is still required for DNA-PK ${ }_{\mathrm{cs}}$ to phosphorylate C1D that is bound to a supercoiled plasmid molecule.

C1D that is associated with supercoiled DNA can direct the phosphorylation of other polypeptides by DNA-PK

The above results reveal that CID interacts with DNA$\mathrm{PK}_{\mathrm{cs}}$ and show that DNA-PK can phosphorylate C1D which is bound to supercoiled plasmid DNA. To see whether C1D can induce DNA-PK to phosphorylate other substrates in the presence of supercoiled DNA and whether it can substitute for Ku in these events, we analyzed the effect of C1D that was bound to supercoiled DNA (C1D-SC) on the ability of DNA-PK to phosphorylate a synthetic pepti de derived from the amino-terminal transcriptional activation region of p53 (Anderson and Lees-M iller 1992; Finnie et al. 1995). As a control, a mutant peptide was used that is not phosphorylated by DNA-PK. Consistent with previous observations, addition of linear DNA to reactions containing both DNA$\mathrm{PK}_{\mathrm{cs}}$ and $\mathrm{Ku}$ was found to result in strong kinase activity (Fig. 4A, lane 4), whereas the p53-derived pepti de is phosphorylated poorly in reactions containing $D N A-P K_{c s}$ al one or containing DNA-PK ${ }_{\mathrm{cs}}$ in the presence of supercoiled DN A (Fig. 4A, lanes 1 and 2, respectively). Moreover, addition of purified $\mathrm{Ku}$, the DN A-end-binding protein poly(ADP)-ribose polymerase (PARP), or bovine serum al bumin (BSA) does not increase DN A-PK-mediated kinase activity in the presence of supercoiled DN A (Fig. 4, lanes 8-10, respectively). However, the inclusion of C1D-Sc in reactions containing DNA-PK ${ }_{c s}$ results in a slight but significant increase in kinase activity compared with that obtained with DNA-PK ${ }_{\mathrm{cs}}$ al one, suggesting that $C 1 D$ is able to activate DNA-PK ${ }_{c s}$ for phosphorylation of other protein targets (Fig. 4A, cf. lanes 1 and 5). Most strikingly, addition of $\mathrm{Ku}$ to such reactions results in kinase activity as strong as that obtained with linear DN A (Fig. 4A, lanes 6,4).

Because C1D used in the above experiments had been refolded onto supercoiled plasmid DNA and because no additional DNA was used, we considered it a possibility that the DNA present in the CID preparation had become degraded, and it was this degraded DN A that led to DN A-PK activation. To determine whether this was the case, the DNA present in the refolded C1D preparation was purified by sequential phenol and chloroform extractions. A nalysis of such DNA by agarose gel electrophoresis revealed that it was still almost enti rely supercoiled (data not shown). M oreover, when this recovered DN A is added to reactions containing $\mathrm{Ku}$ and $\mathrm{DNA}-\mathrm{PK}_{\mathrm{cs}}$, no significant stimulation of DNA-PK-mediated p53 peptide kinase activity is observed (Fig. 4A, lane 7). Therefore, 
A

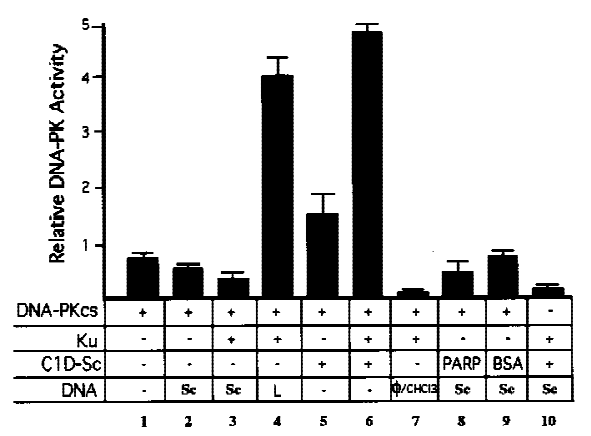

B

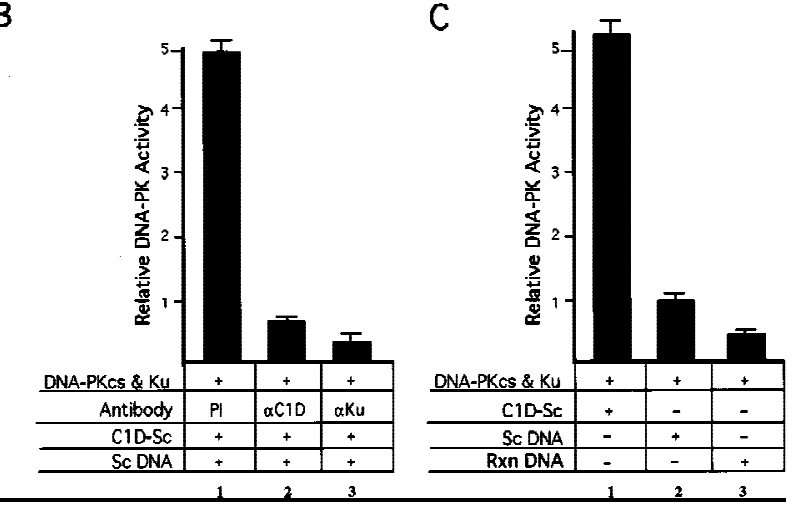

Figure 4. CID activates DNA-PK when bound to a supercoiled plasmid. (A) DN A-PK activity was tested by standard DNA-PK peptide assays (see Materials and Methods) in the presence of the indicated components. In reactions 8 and 9, PARP or BSA were used instead of C1D-Sc. A total of $800 \mathrm{ng}$ of C1D-Sc was subjected to sequential phenol/chloroform extraction ( $\phi /$ $\mathrm{CHCl}_{3}$ ) and the DNA was precipitated, resuspended in a small amount of water, and added into reaction 7 (this amount of DNA is in excess of the amount in $100 \mathrm{ng}$ of C1D-Sc; lanes $5,6,10)$. Where indicated, $100 \mathrm{ng}$ of excess supercoiled (Sc) or linear (L) DN A was added. (B) Proteins were incubated with the indicated antibodies for $30 \mathrm{~min}$ on ice and the kinase reaction was started by adding [ $\gamma^{32}$ P]ATP. The anti-C 1D antiserum used in this experiment was raised against the GST-C1D fusion and, therefore, is a distinct derivative from the recombinant Histagged version of C1D used in the kinase assay. (C) DNA-PK peptide phosphorylation assays were conducted with the indicated components. To generate the Rxn DN A, a standard kinase assay was conducted containing C1D-Sc, DNA-PK ${ }_{\mathrm{cS}}$ and $\mathrm{Ku}$, then the DNA was retrieved by $\phi / \mathrm{CHCl}_{3}$ extraction and precipitation.

the supercoiled DNA to which C1D was bound had not become degraded. To address the possi bility that a nuclease might exist in C1D preparations and become active only under kinase assays conditions, we incubated C1DSc and DNA-PK together under kinase assay conditions (containing $\mathrm{Mg}^{2+}$ ) with a radiolabeled DNA fragment. No degradation of the DNA was detectable when it was subsequently analyzed al ongside its untreated control by electrophoresis on a denaturing urea/ polyacrylamide gel (data not shown). As a final control, we assembled a kinase reaction containing CID-Sc, DNA-PK $\mathrm{CS} / \mathrm{Ku}$, incubated this under kinase assay conditions, and then extracted the DNA. As shown in Fig. 4C, this DNA (Rxn
DNA) was unable to promote DNA-PK activation, re vealing that it had not become degraded. Taken together, these results show that the C ID preparation used is devoid of detectable nuclease activity and reveal that DNA-PK activation ensues only when supercoiled plasmid DNA is complexed to C1D. In addition, they reveal that $\mathrm{Ku}$ is required for $\mathrm{DNA}-\mathrm{PK}_{\mathrm{cs}}$ to be stimulated maximally by C1D-Sc. To confirm these conclusions, reactions containing DNA-PK ${ }_{\mathrm{cs}}$ and Ku together with C1DSc were preincubated for $30 \mathrm{~min}$ with either preimmune serum, anti-C1D antiserum, or anti-Ku antiserum, before being tested for phosphorylation of the p53-derived peptide (Fig. 4B). These studies revealed that whereas incubation with prei mmune serum does not affect DN APK mediated kinase activity significantly, kinase activity is essentially abolished on incubation with either anti-C1D antiserum or with anti-Ku antiserum (the antiC1D antiserum used here was rai sed against a different recombinant version of C1D than that used in the kinase assay; see legend to Fig. 4B for details). These results, therefore, reinforce the notion that both CID and Ku are required for the efficient activation of DNA-PK ${ }_{c s}$ by supercoiled DNA.

Because the above studies utilized a synthetic peptide derived from $\mathrm{p} 53$, and because $\mathrm{p} 53$ has been implicated recently as an in vivo target for DNA-PK (Shieh et al. 1997), we tested whether similar effects are obtained with the full-length p53 protein. Importantly, virtually no protein phosphorylation is observed in assays with either DNA-PK (DNA-PK ${ }_{c s}$ plus Ku), p53, or C1D-Sc alone (Fig. 5A, lanes 1-3). Furthermore, and consistent with previous work, p53 phosphorylation by DNA-PK is very poor in the absence of added DN A (Fig. 5A, lane 5), and is stimulated strongly by the addition of linear DN A (lane 6) but not by supercoiled DN A (lane 7). Hence, in the absence of C $1 D$, efficient phosphorylation of p53 by DNA-PK is dependent on the DNA in the assay being linear. In contrast, when supercoiled DNA is used that has been assembled with C1D, p53 is phosphorylated as efficiently as it is in the presence of linear DN A (Fig. 5A, lane 8; C1D is also phosphorylated under these conditions). Because addition of increasing amounts of supercoiled plasmid DNA or purified supercoiled DNA derived from the refol ded C1D preparation (see above) does not cause any increase in p53 phosphorylation (data not shown), we conclude that the ability of DNA-PK to phosphorylate p53 in the presence of supercoiled DNA is dependent on C1D. In line with this and with results obtained with the peptide phosphorylation studies, the phosphorylation of the p53 protein is inhibited by preincubation with anti-C1D or anti-Ku serum but not with preimmune serum (Fig. 5B).

\section{DNA-PK and C1D can interact in mammalian cells}

In light of the above data, we wished to test whether DNA-PK ${ }_{\text {cs }}$ and C1D are capable of interacting with one another in mammalian cells. Furthermore, because the interaction between DNA-PK and the protein c-Abl has been shown to be stimulated in response to DN A dam- 
$\mathbf{A}$

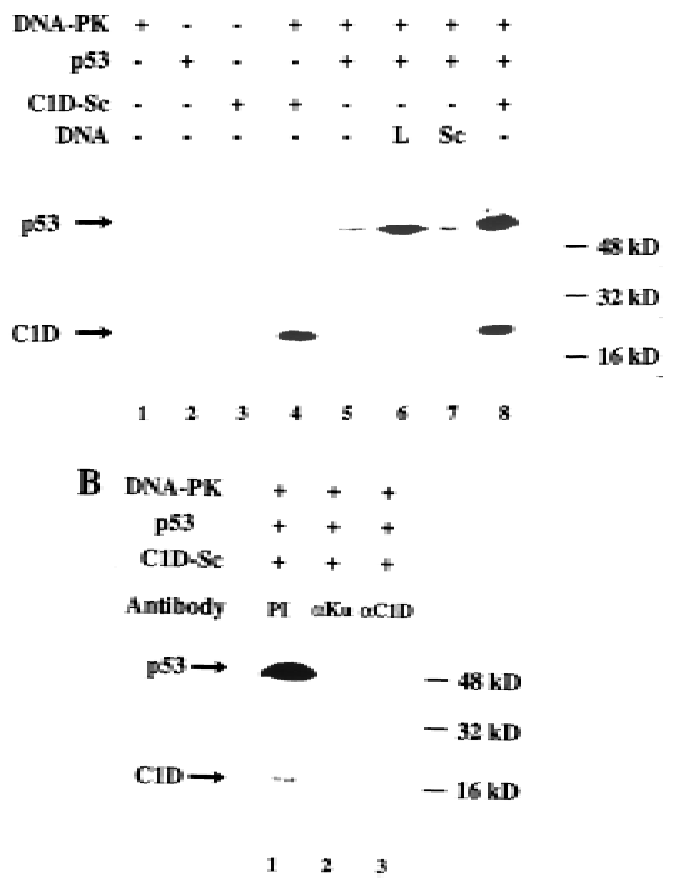

Figure 5. CID can activate DNA-PK to phosphorylate fulllength $\mathrm{p} 53$, and this activation is C1D-dependent. (A) DN A-PK, C1D-Sc, and p53 were incubated as described in Materials and M ethods. Where indicated, $100 \mathrm{ng}$ of linear (L) or supercoiled (Sc) plasmid was included. (B) Assays were conducted as in A, except that proteins were incubated with the indicated antibodies before reactions were initiated by the addition of $\left[\gamma^{-}{ }^{32}\right.$ P]ATP.

age (Kharbanda et al. 1997), we wanted to determine whether this is also the case for the interaction between CID and DNA-PK ${ }_{\mathrm{cs}}$. Although initial experiments were designed to address an interaction between endogenous mammalian cell C1D and DNA-PK ${ }_{\mathrm{cs}}$ in coimmunoprecipitation assays, such studies were not feasible because C1D remains tightly bound to DN A during whole cell or nuclear extract preparation and, consequently, is not detectable by Western blotting of soluble cell extracts (N ehls et al. 1998; U. Yavuzer, unpubl.). To circumvent this problem, we expressed recombinant C1D in mammalian cells in anticipation that a fraction of the expressed protein would remain soluble following cell extract preparation. Thus, COS cells were transiently transfected with a vector expressing an HA epitopetagged version of human C1D. After $48 \mathrm{hr}$, lysates were prepared from the transfected cells with or without prior exposure to $15 \mathrm{~Gy}$ of IR, and were immunoprecipitated with anti-DNA-PK ${ }_{\mathrm{cs}}$, anti-HA, or preimmune sera. The immunoprecipitates were then analyzed by Western blotting with an anti-HA antibody or an anti-DNA-PK antiserum. As shown in Figure $6 \mathrm{~A}$, a protein of $\sim 22 \mathrm{kD}$ is detected by the anti-HA antibody in anti-DNA-PK ${ }_{\mathrm{cs}} \mathrm{im}$ munoprecipitates derived from transfected cells (Fig. 6A, lanes 2,4$)$. In contrast, no such protein is evident when extracts of transfected cells are immunoprecipitated with preimmune serum (Fig. 6A, lanes 1,3), nor when extracts of untransfected cells are immunoprecipitated with the anti-DNA-PK ${ }_{\mathrm{cs}}$ antiserum (lane 6). When the blot was stripped and reprobed with an anti-C 1D antiserum, the protein of $\sim 22 \mathrm{kD}$ was again detected in antiDN A-PK ${ }_{\mathrm{cs}}$ immunoprecipitates derived from transfected cells (data not shown). In light of these results, and because the predicted molecular mass of HA-tagged C 1D is $\sim 22 \mathrm{kD}$, these data suggest strongly that the protein immunoprecipitated by the anti-DNA-PK ${ }_{\mathrm{cs}}$ antisera from extracts of transfected cells is C1D.

To further verify the interaction between DNA-PK ${ }_{c s}$ and C1D detected above, we conducted the immunoprecipitation experiments in reverse by analyzing immunoprecipitates of C1D for the presence of DNA-PK ${ }_{\mathrm{CS}}$. N otably, DNA-PK ${ }_{\mathrm{cs}}$ is recovered in anti-HA immunoprecipitates of cells transfected with the HA-C1D expression construct (Fig. 6B, lane 2 ) but is not evident in preimmune immunoprecipitates of transfected cell extracts or in anti-HA immunopreci pitates from extracts of untransfected cells (Fig. 6B, lanes 1 and 4, respectively). Taken together, these data indicate that C1D interacts with DNA-PK ${ }_{c s}$ in unfractionated mammalian cell ex-

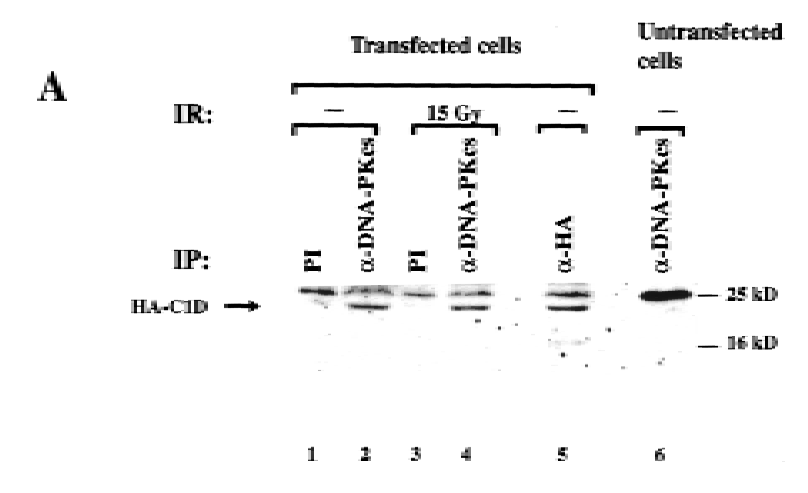

Westem Blot: anti-HA

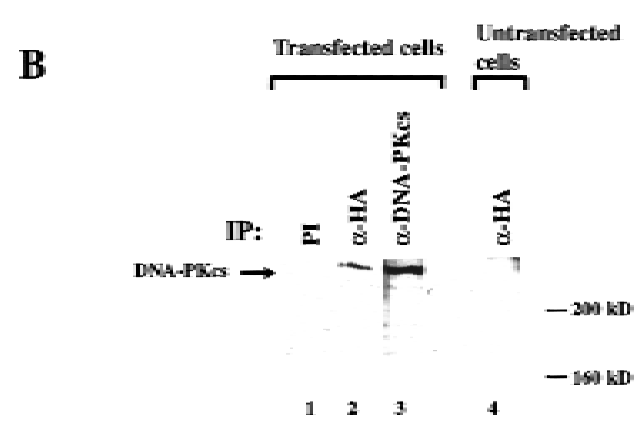

Western Blot: DNA-PKes

Figure 6. CID and DNA-PK ${ }_{\mathrm{cs}}$ interact in mammalian cells. (A) Lysates from untransfected (lane 6) or HA-C1D-transfected COS cells (lanes 1-5) were immunoprecipitated with preimmune (PI), anti-DN A-PK ${ }_{\mathrm{cs}}$ or anti-HA antisera. For lanes 3 and 4 , the cells were treated with $15 \mathrm{~Gy}$ of ionizing irradiation before lysate preparation. Western blotting was performed by an anti-HA antibody. The higher band is the IgG light chain (25 $k D$ ). (B) Lysates from transfected and untransfected cells were immunoprecipitated with the antisera described in $A$, and the Western blot was developed by anti-DNA-PK $\mathrm{cs}$ antibody. 
tracts. Significantly, however, and in contrast to the situation reported for the interaction between DNA-PK and c-Abl, no significant change in the association between CID and DNA-PK ${ }_{\mathrm{cs}}$ is evident in response to IR (Fig. 6A, cf. lanes 2 and 4).

\section{CID is induced in response to IR}

Although DNA damage has been shown to activate the kinase activity of DNA-PK in vitro, the molecular mechanisms underlying activation of DNA-PK in vivo have yet to be established. One possibility is that the interaction between CID and DN A-PK ${ }_{c s}$ plays some role in the regulation of DNA-PK activity in vivo in response to DNA damage. No difference in the association between DNA-PK and C1D in response to DNA damage was detected in the transfection assays described above. However, because C1D expression in these experiments was under the control of a heterologous promoter, any potential effects of IR on C1D expression may have been overlooked. Therefore, we analyzed C1D levels in total cell lysates by Western immunoblot analysis either before or after exposing cells to $15 \mathrm{~Gy}$ of IR. As shown in Figure 7A (left), following IR treatment there is robust induction in the levels of a protein of $\sim 18 \mathrm{kD}$ (the predicted size of endogenous (1D) that is recognized by an antiserum raised against recombinant His-tagged C1D. In contrast, no significant induction of this protein was observed in response to UV irradiation. To confirm that the protein induced by IR is C ID, the bl ot was stripped

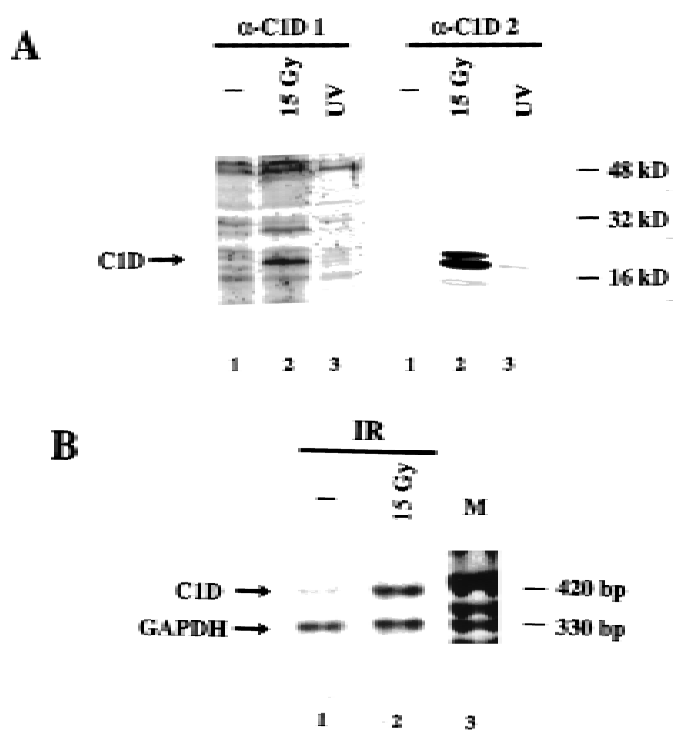

Figure 7. CID is induced in response to IR. (A) T otal cell lysate from cells with or without prior exposure to $15 \mathrm{~Gy}$ of IR was resolved by SDS-PAGE and transferred onto nitrocellulose. Western blotting was performed by antibodies raised against a His-tagged C1D ( $\alpha$-C1D 1) or GST-C1D ( $\alpha$-C1D 2$)$ fusion proteins. (B) C1D transcript expression in nonirradiated and irradiated cells. RT-PCR was performed on RNA extracted from irradiated or noni rradiated cells, and CDNA amplified by primers described in Materials and Methods. GAPDH was used as an internal control. and reprobed with another $C 1 D$ antibody raised against a GST -C ID fusion protein ( $\alpha$-C 1D 2). As seen in Figure 7A (right), the same $\sim 18 \mathrm{kD}$ protein band is recognized by this second antibody, providing strong evidence that it is C1D. To determine whether the induction of C1D is at the mRN A level, RN A prepared from irradiated and nonirradiated cells was analyzed by quantitative RT PCR. As shown in Figure 7B, C1D mRN A levels are barely detectable in nonirradiated cells but are induced $\sim 10$-fold on exposing cells to IR. Significantly, no difference is observed in the level of GAPDH expression between irradiated and nonirradiated cells. Thus, both C1D protein and $\mathrm{mRN} A$ are increased in response to $\gamma$-irradiation.

\section{Discussion}

Previous work on DN A-PK has revealed that its catalytic activity in vitro is stimulated markedly by the presence of free DNA ends. Although DNA-PK ${ }_{c s}$ itself has been shown recently to have an inherent capability to bind to and be activated by DN A DSBs (Yaneva et al . 1997; Hammarsten and Chu 1998), efficient activation of the enzyme in vitro requires the DNA end-binding protein $\mathrm{Ku}$. In line with DN A-PK ${ }_{\mathrm{cs}}$ and $\mathrm{Ku}$ functioning in concert in vivo, the loss of either component leads to defects in DNA DSB repair and $V(D) J$ recombination in cell lines and animal systems. These observations suggest strongly that DNA-PK is recruited to DSBs in vivo. The results presented in this manuscript reveal an alternative mechanism by which DN A-PK catal ytic activity may be regulated. Specifically, we show that DNA-PK can be activated in the absence of DSBs through association with the recently identified $\sim 18-k D$-cellular protein termed C1D. This suggests that al ternative mechanisms may exist for DNA-PK activation in vivo.

Using the yeast two-hybrid approach to screen a human B-Iymphocyte library, we have discovered that C ID binds specifically to the putative LZ motif of DNA-PK ${ }_{c s}$. Furthermore, we have demonstrated the importance for the DNA-PK ${ }_{c s}$ LZ motif by showing that point mutations of key residues within it severely inhibit the twohybrid interaction with C1D. In addition, we have established that full-length derivatives of DNA-PK ${ }_{c s}$ and C ID can interact in vitro and in vivo, either as purified proteins or when they are present in unfractionated mammalian cell extracts. Significantly, the binding of DNA$\mathrm{PK}_{\mathrm{cs}}$ to C ID appears to be direct, as evidenced by the fact that it does not require DNA and is not disrupted by the addition of ethidium bromide. In contrast, no direct interaction between $\mathrm{C} 1 \mathrm{D}$ and $\mathrm{Ku}$ is detectable by the assays that we have used, al though $\mathrm{Ku}$ does appear to associate with CID indirectly via DNA-PK ${ }_{\mathrm{cs}}$ in the presence of DNA. The apparent ability of DNA-PK $c$ to contact CID and Ku simultaneously is consistent with the fact that the region of DNA-PK ${ }_{\mathrm{cs}}$ that interacts with C1D is distinct from that which has been shown recently to bind Ku (Shengfang et al. 1997).

C1D was identified initially as an antigen that remains associated with DNA even after treatment with harsh denaturants. When expressed in bacteria, C1D is highly 
insoluble in the absence of ionic detergents such as SDS, or chaotropic agents such as urea or guanidine hydrochloride. However, if C1D is solubilized in the presence of $8 \mathrm{~m}$ urea and the urea is then removed slowly by dialysis, C1D is able to refold onto DNA that is provided. By taking advantage of this property of C1D, we have shown that it is a very good substrate for DNA-PK mediated phosphorylation. Furthermore, we have found that DNA-PK is able to phosphorylate CID not only when it has been refolded onto a linear DNA molecule but also when C1D is bound to a supercoiled plasmid. Several lines of evidence indicate that the activation of DNA-PK in this latter instance requires C1D. First, when the supercoiled DN A used to refold C1D was retrieved by repeated phenol/chloroform extractions and was then analyzed by agarose gel electrophoresis, it was still found to exist almost exclusively in supercoiled form. Second, this retrieved DN A was unable to activate DNA-PK in phosphorylation assays containing either a synthetic peptide or the full-length p53 protein. Thus, the DNA that had been associated with C1D had not sustained nicks or DSBs that could have allowed it to activate DNA-PK directly. Third, we have not detected any nuclease activities in our CID preparations that are activated on incubation under kinase assay conditions. Finally, the stimulation of DNA-PK activity by C1D in association with supercoiled DNA is inhibited by antibodies raised against C 1D but not by any of the preimmune antisera we have tested.

Taken together, the available data suggest a model whereby DNA-PK can be activated in the absence of DN A ends. In this model, the interaction between C ID and DNA-PK ${ }_{c s}$ serves as a mechanism to target DNA$\mathrm{PK}_{\mathrm{cs}}$ to a DN A molecule. However, this complex appears to be inactive catal ytically, because we have observed no phosphorylation of CID or other proteins when DNAbound CID is incubated with DNA-PK ${ }_{c s}$ alone. Rather, DNA-PK ${ }_{c s}$ activity is only triggered when Ku subsequently enters the complex. One explanation for the demand for Ku despite the lack of DNA ends is that C ID alters the conformation of DNA-PK so that it is able to bind to Ku without DNA ends. Alternatively, it is possible that the binding of C1D to DNA alters the DNA structure so that it is now able to interact with $\mathrm{Ku}$, and consequently, trigger the ability of $\mathrm{Ku}$ to bind and activate DNA-PK ${ }_{\mathrm{cs}}$. In this model, the inhibition of kinase activity mediated by antibodies that recognize C1D or $\mathrm{Ku}$ could be through them, preventing the assembly of the multiprotein complex, and the inhibition effected by ethidium bromide could be brought about by disruption of the Ku-DNA and/or C1D-DNA interactions. Finally, active DNA-PK may then phosphorylate various target proteins, including C1D itself. Although the consequences of C1D phosphorylation by DNA-PK are currently unclear, it is tempting to speculate that this activates C1D for some additional function(s), or dissociates the complex between C1D and DNA-PK ${ }_{\mathrm{cs}}$ once its function is complete.

What could be the physiological role(s) for the interaction between CID and DNA-PK $\mathrm{cs}_{\mathrm{c}}$ and the model for
DNA-PK activation described above? One potential clue is provided by the fact that CID binds to DNA in an extremely stable fashion, as evidenced by the fact that it remains DN A-associated even after rigorous extraction procedures. Highly stable nonhistone proteins that are bound to DNA tightly have been identified in various systems, including insects, plants, and mammal ian cells (Krauth and Werner 1979; Capesi us et al. 1980; Bodnar et al. 1983; Avramova and Tsanev 1987). Although the biological functions for these proteins are still largely obscure, it is noteworthy that some have been reported to be associated with highly repetitive DN A sequences and to be involved in targeting a subset of genomic DNA to the nuclear matrix (Neuer and Werner 1985; NeuerN itsche et al. 1988; Werner and Neuer-N itsche 1989; Pfutz et al. 1992). This is of particular interest in regard to the results described herein, as the nuclear matrix is thought to provide the structural framework for nuclear/ chromatin organization, and has been shown to associate with several nuclear metabolic processes including DNA replication, transcription, RNA splicing, topoisomerase activity, nucleotide excision repair, and DN A DSB repair (Berezney 1984; Cockerill and Garrard 1986; Nelson et al. 1986; Verheijen et al. 1988; Jackson 1991; Kaufman and Shaper 1991; Y asui et al. 1991, 1994; Korte and Y asui 1993; Johnston and Bryant 1994; Koehler and Hanawalt 1996).

By operational definitions, C1D is a nuclear matrixassociated protein and can be detected in nuclear matrix preparations by Western immunoblots and immunofluorescence. CID is also induced by $\gamma$-irradiation. Therefore, it is possible that CID targets DNA-PK to the nuclear matrix and matrix-associated DNA in response to DNA damage. Once DNA-PK is activated, it is possible that it may then al low proteins involved directly in DN A repair to perform their functions. Alternatively, or in addition, C1D might target DNA-PK to the nuclear matrix constitutively. Evidence in support of the notion that DNA-PK function is linked to the nuclear matrix comes from the observation that the radiosensitive cell line xrs5, which is deficient in Ku80, exhibits irregularly shaped nuclei, has nuclear envel ope abnormalities, and has altered nuclear matrix attachment regions with re spect to wild-type cells (Yasui et al. 1991, 1994; Korte and Y asui 1993). Furthermore, this cell line has al so been shown to be defective specifically in the joining of matrix attached DNA DSBs (Johnston and Bryant 1994). This suggests that the targeting of both DNA-PK and DNA to the nuclear matrix may play a crucial role in DN A DSB repair processes. Studies into interactions between DNA-PK and C1D, and possibly also with other matrix associated proteins, should help address this important issue.

\section{Materials and methods}

Cloning, mutagenesis, and DNA sequencing

pLexA-LZ $Z_{c s}$ was generated by cloning into the Spel site of pBTM 116PS, the region of the DNA-PK ${ }_{\mathrm{cs}} \mathrm{CDN}$ A corresponding 
to nucleotide residues 4560-4860 (containing a natural $5^{\prime}$ and a polylinker-derived 3' Xbal sites). pBT M 116PS was derived from plasmid pBTM 116 (obtained from S. Elledge, HHMI, Baylor College of Medicine, Houston, TX) by modifying the frame of the cloning site and the addition of polystop codons. To construct the wild-type $L Z$ region of DNA-PK ${ }_{c s}$ as a VP16 fusion $\left(L_{c s}-\right.$ VP16), nucleotide residues $4381-4860$ were amplified by PCR with a $5^{\prime}$ Notl site and Xhol-Notl sites on $3^{\prime}$ end, and cloned into pVP16 (obtained from S. Hollenberg) as well as pBlueskript $\mathrm{SK}^{+}\left(\mathrm{pBSK}^{+}\right)$as a Notl fragment. M ut1LZ $\mathrm{cs}^{-\mathrm{VP} 16}$ was isolated in two steps. First, DN A-PK ${ }_{\mathrm{cs}}$ nucl eotide residues 4560-4860 were isolated by PCR with mismatch primers placing an Xbal site at the $5^{\prime}$ end and Xhol and Notl sites at the $3^{\prime}$ end, then replacing this by the Xbal-Xhol fragment of wild-type $L Z_{\mathrm{cs}}$ in $\left(\mathrm{pBSK}^{+}\right)$. Second, the whole fragment containing the entire $L Z$ region of DNA-PK ${ }_{c s}$ in which the second leucine is mutated to a proline was cut out as a Notl fragment and cloned into pVP16. Mut2LZ $\mathrm{Cs}_{\text {-VP16 }}$ was isolated as a linker-scanner mutation. Nucleotide residues $4601-4860$ were isolated by PCR with primers placing BamHI and Notl sites on the $5^{\prime}$ and $3^{\prime}$ ends, respectively. Residues 4381-4601 were isolated by PCR with a $5^{\prime} \mathrm{Notl}$ and $3^{\prime}$ BamHI site at each end and both fragments were cloned into Notl site in pVP16 allowing the two fragments to join at the BamHI site in the middle, which mutates the third leucine to a proline and the preceding glutamic acid to aspartic acid. For bacterial and mammalian CID expression constructs, the ORF of C1D was isolated by PCR with primers placing suitable restriction sites to the $5^{\prime}$ and $3^{\prime}$ ends and cloning intoexpression plasmids. Bacterial expression plasmids are: pGEX (Pharmacia), pQE30 (Qiagen expression systems). For the mammalian expression construct, an HA epitope (a peptide derived from influenza hemaggl utinin protein)-tagged expression vector pCMV 5'2N 3T (Lavender et al. 1997) was used. Sequencing of PCR fragments, point mutations, and CDNA inserts from positive clones of the two-hybrid screen was performed with an automatic sequencer by the dideoxy termination method. Sequence comparisons were conducted by GenBank database searches.

\section{Yeast two-hybrid screen}

A human B-lymphocyte CDNA library in pACT was used (Harper et al. 1993). The other components of the system were provided by $\mathrm{S}$. Hollenberg. Saccharomyces cerevisiae L40 (MATa trp1 leu2 his3 LYS2:I exA-HIS3 U RA3::IexA-lacZ) was grown at $30^{\circ} \mathrm{C}$ in YPD medium (1\% yeast extract, $2 \%$ polypepton, and $2 \%$ glucose), was sequential ly transformed with plexA$\mathrm{LZ}_{\mathrm{cs}}$ and human B-lymphocyte CDNA library by the lithium acetate method. Double transformants were plated on yeast dropout medium lacking Trp, Leu, His, Lys, and uracil and were grown at $30^{\circ} \mathrm{C}$ for 3 days. Colonies were then transferred on Whatman 40 filters to test for $\beta$-galactosidase activity [with an $X$-gal (5-bromo-4-chloro-3-indolyl- $\beta$-D-gal actopyranoside) colony filter assay]. Positive clones were rescued and tested for specificity by transformation into $\mathrm{L} 40$ either with plexA-LZ $\mathrm{Cs}_{\mathrm{cs}}$ or control plasmids plexA-Lamin, plexA-Daughterless, or plexA alone.

\section{Bacterial expression and purification of C1D}

Expression of GST (C1DpGEXTK2) or His-tagged C1D (C1DpQE30) fusion proteins was induced for $4 \mathrm{hr}$ by adding 2 mM IPTG (isopropyl- $\beta$-O-thiogal actopyroniside) and the fusion proteins were isolated from bacterial lysates by affinity chromatography by use of gl utathione-agarose beads (Sigma) or $\mathrm{Ni}$ NTA agarose (Qiagen) columns, respectively. C1D pQE30 fusion protein was purified under denaturing conditions in the presence of $8 \mathrm{M}$ U rea and dialyzed against $0.1 \times T E$ in the presence of linear or supercoiled plasmid DNA. Antibodies against the recombinant proteins were raised in rabbits by standard procedures (Harlow and Lane 1988).

\section{GST-pull-down assays}

Purified DNA-PK ${ }_{\mathrm{cs}}, \mathrm{Ku}$, or the DN A-PK holoenzyme was incubated for $2 \mathrm{hr}$ with fusion protein bound to glutathione-coupled agarose beads (Hagemeier et al. 1994). Precipitates were washed several times with NETN (20 mM Tris at pH 8.0, $100 \mathrm{~mm} \mathrm{~N} \mathrm{aCl}$, $1 \mathrm{~mm}$ EDTA and $0.5 \%$ N P-40) and were subjected to SDS-PAGE and Western blotting. The GST-CBP protein (CPB1; Bannister and Kouzarides 1995) used as a control contained amino acid residues 461-662 of CBP.

\section{Kinase assays}

Two nanograms of purified DNA-PK ${ }_{\mathrm{cs}}$ together with $5 \mathrm{ng}$ of $\mathrm{Ku}$ or $60 \mathrm{ng}$ of DN A-PK holoenzyme was incubated for 2 min with $100 \mathrm{ng}$ of C1D pQE refolded on a linear or a supercoiled DNA in the presence of $20 \mu \mathrm{l}$ of $Z^{\prime}$ buffer $(25 \mathrm{~mm}$ HEPES-KOH at pH 7.9, $50 \mathrm{mM} \mathrm{KCl}, 10 \mathrm{~mm} \mathrm{M} \mathrm{gCl} 2,20 \%$ glycerol, $0.1 \% \mathrm{NP}-40,1 \mathrm{~mm}$ DTT, and $200 \mu \mathrm{M}$ ATP) and the reaction was started by adding $10 \mu \mathrm{Ci}$ of $\left[\gamma^{-32} \mathrm{P}\right] \mathrm{ATP}(6000 \mathrm{Ci} / \mathrm{mmole})$. Following incubation at $30^{\circ} \mathrm{C}$ for $20 \mathrm{~min}$, phosphorylated proteins were subjected to $20 \%$ SDS-PAGE and visualized by autoradiography. When used, antibodies, ethidium bromide $(200 \mu \mathrm{g} / \mathrm{ml})$, or LY $294002(2.5 \mu \mathrm{m}$ final concentration), were incubated on ice with the proteins for $30 \mathrm{~min}$ before starting kinase reactions. The amount of excess linear DNA was $100 \mathrm{ng}$. DNA-PK peptide phosphorylation assays were conducted as described previously (Finnie et al. 1995). Relative DNA-PK activity was calculated by subtracting the $\mathrm{cpm}$ incorporated into mutant peptide from the cpm incorporated into wild-type peptide, then dividing this by cpm incorporated by mutant peptide.

\section{Cell culture and transient transfections}

COS 7 (African green monkey kidney), HeLa, or N IH-3T 3 cells were maintained in DMEM supplemented with $10 \%$ fetal calf serum and grown at $37^{\circ} \mathrm{C}$ with $10 \% \mathrm{CO}_{2}$ as monolayers. Transfections were performed by the cal cium phosphate precipitation technique. The precipitate was left on the cells for 8-10 hr before a glycerol shock ( $15 \%$ glycerol for $1 \mathrm{~min}$ ) was given. Cells were then washed twice with PBS and fresh medium was added and cells were harvested $48 \mathrm{hr}$ after transfection.

\section{Coimmunoprecipitations}

Five micrograms of HA-C1D was transfected into $1 \times 10^{8}$ COS or NIH-3T 3 cells as described above. Forty-eight hours following transfection, cells were harvested and lysed in Iysis buffer ( $150 \mathrm{~mm} \mathrm{~N} \mathrm{aCl}$ with $0.2 \% \mathrm{NP}-40$ ). Cells that were subjected to $15 \mathrm{~Gy}$ of ionizing irradiation were incubated for $1 \mathrm{hr}$ at $37^{\circ} \mathrm{C}$ before harvesting. Lysates were incubated with appropriate sera for $1 \mathrm{hr}$ on ice and bound to protein A- or G-Sepharose for $4 \mathrm{hr}$, rocking gently at $4^{\circ} \mathrm{C}$. Precipitates were then washed three times with the lysis buffer (15 min each), separated by $15 \%$ SDS-PAGE, and blotted onto nitrocellulose. Western blotting was performed with anti-HA monoclonal antibody (12CA5, Boehringer) or a polyclonal antiserum raised against the fulllength DNA-PK ${ }_{\mathrm{cs}}$ and immunoreactive bands were revealed by an ECL kit (Amersham) according to the manufacturer's instructions. 


\section{RT-PCR}

Total RNA from irradiated or nonirradiated cells was prepared as described (Sambrook et al. 1989), and $1 \mu \mathrm{g}$ of RN A was used to reverse transcribe according to the enzyme manufacturer's instructions (Boehringer M annheim). The CDNA was then amplified with the primers 5'-ATGGCAGGTGAAGAAATT and 3'-ACTTTTACTTTTTCCTTT (CID) that generates a 420-bp fragment of the CID CDNA, and the primers 5 -CCACAGTCCATGCCATCACTG and 3'-CGCTGTTGAAGTCAGAGGAGA for a 340-bp fragment of the human GAPDH cDNA. Each PCR cycle consisted of incubation periods of $30 \mathrm{sec}$ at $95^{\circ} \mathrm{C}, 1 \mathrm{~min}$ at $55^{\circ} \mathrm{C}$, and $1 \mathrm{~min}$ at $72^{\circ} \mathrm{C}$. PCR products were then analyzed on a $2 \%$ agarose gel. To ensure that the PCR reaction was quantitative, aliquots of each PCR reaction were analyzed every 4 cycles, between 12 and 32 cycles.

\section{Acknowledgments}

We thank members of the S.P.J. laboratory for their support. Many thanks also to C.R. Goding and T. Kouzarides for their valuable comments and to Steve Elledge and Stan Hollenberg for yeast two-hybrid system components. U.Y. was supported by a Special Fellowship from the Leukemia Society of America, and this work was funded by grants from the Cancer Research Campaign.

The publication costs of this article were defrayed in part by payment of page charges. This article must therefore be hereby marked "advertisement" in accordance with 18 USC section 1734 solely to indicate this fact.

\section{Note added in proof}

C1D is apparently identical to the protein SUN-CoR, which has recently been identified as a putative transcriptional corepressor (Zamir et al. 1997 Proc. Natl. Acad. Sci. 94: 14400-14405).

\section{References}

Alt, F.W., E.M. Oltz, F. Young, J. Gorman, G. Taccioli, and J. Chen. 1992. VDJ recombination. Immunol. Today 13: 306314.

Anderson, C.W. and S.P. Lees-Miller. 1992. The nuclear serine/ threonine protein kinase DNA-PK. Crit. Rev. Eukaryot. Gene Expr. 2: 283-314.

Avramova, Z. and R. Tsanev. 1987. Stable DNA protein complexes in eukaryotic chromatin. J. Mol. Biol. 196: 437-440.

Bannister, A.J. and T. Kouzarides. 1995. CBP-induced stimulation of c-Fos activity is abrogated by E1A. EMBO J. 14: 47584762.

Berezney, R. 1984. Organization and function of the nuclear matrix. Chrom. Non-Histone Proteins 4: 119-179.

Bodnar, J.W., C.J. Jones, D.H. Coombs, G.D. Pearson, and D.C. Ward. 1983. Proteins tightly bound to HeLa cell DNA at nuclear matrix attachment sites. Mol. Cell. Biol. 3: 15671579.

Boulton, S.J. and S.P. Jackson. 1998. Components of the Kudependent non-homologous end-joining pathway are involved in telomeric length maintenance and telomeric silencing. EMBO J. 17: 1819-1828.

Capesius, I., W. Krauth, and D. Werner. 1980. Proteinase Kresistant and alkali-stably bound proteins in higher plant DN A. FEBS Lett. 110: 184-186.

Cockerill, P.N . and N.T. Garrard. 1986. Chromosomal loop anchorage of immunoglobin genes occurs adjacent to enhanc- ers via DN A elements possesing topoisomerase-II sites. Cell 44: 273-282.

Dvir, A., L.Y. Stein, B.L. Calore, and W.S. Dynan. 1993. Purification and characterization of a template-associated protein kinase that phosphorylates RNA polymerase II. J. Biol. Chem. 268: 10440-10447.

Fields, S. and O. Song. 1989. A novel genetic system to detect protein-protein interactions. Nature 340: 245-246.

Finnie, N.J., T.M. Gottlieb, T. Blunt, P. Jeggo, and S.P. Jackson. 1995. DN A-PK activity is absent in xrs-6 cells; implications for site-specific recombination and DNA double-strand break repair. Proc. Natl. Acad. Sci. 92: 320-324.

Gellert, M. 1992. Molecular analysis of V(D)J recombination. Annu. Rev. Genet. 22: 425-446.

Gottlieb, T.M. and S.P. Jackson. 1993. The D N A-dependent protein kinase: Requirement for DNA ends and association with Ku antigen. Cell 72: 131-142.

Hagemeier, C., R. Caswell, G. Hayhurst, J. Sinclair, and T. Kouzarides. 1994. Functional interaction between the HCMV IE2 transactivator and the retinoblastoma protein. EMBO J. 13: 2897-2903.

Hammarsten, O. and G. Chu. 1998. DNA-dependent protein kinase: DNA binding and activation in the absence of $\mathrm{Ku}$. Proc. Natl. Acad. Sci. 95: 525-530.

Harlow, E. and D. Lane. 1988. Immunizations. In Antibodies. A laboratory manual, pp. 53-137. Cold Spring Harbor Laboratory Press, Cold Spring Harbor, NY.

Harper, J.W., G.R. Adami, N. Wei, K. Keyomarsi, and S.J. Elledge. 1993. The p21 CDK-interacting protein CIP1 is a potent inhibitor of $\mathrm{Gl}$ Cyclin-dependent kinases. Cell 75: 805-806.

Hartley, K.O., D. Gell, G.C.M. Smith, H. Zhang, N. Divecha, M.A. Connelly, A. Admon, S.P. Lees-Miller, C.W. Anderson, and S.P. Jackson. 1995. DN A-dependent protein kinase cataIytic subunit: A relative of phosphatidylinositol 3-kinase and the ataxia telangiectasia gene product. Cell 82: 849-856.

Hollenberg, S.M., R. Sternglanz, P.F. Cheng, and H. Weintraub. 1995. Identification of a new family of tissue-specific basic helix-loop-helix proteins with a two hybrid system. Mol. Cell. Biol. 15: 3813-3822.

Jackson, D.A. 1991. Structure-function relationships in Eukaryotic nuclei. BioEssays 13: 1-10.

Jackson, S.P. 1996. DN A damage detection by DN A dependent protein kinase and related enzymes. Cancer Surv. 28: 261279.

-_-. 1997. DNA-dependent protein kinase. Int. J. Biochem. Cell. Biol. 29: 935-938.

Jackson, S.P. and P.A. Jeggo. 1995. DN A double-strand break repair and $V(D)$ J recombination: Involvement of DNA-PK. Trends Biochem. Sci. 20: 412-415.

Johnston, P.J. and P.E. Bryant. 1994. A component of DNA double-strand break repair is dependent on the spatial orientation of the lesions within the higher order structures of chromatin. Int. J. Radiat. Biol. 66: 531-536.

Kaufman, S.H. and J.H. Shaper. 1991. Association of topoisomerase II with the hepatoma cell nuclear matrix: The role of intermolecular disulfide bond formation. Exp. Cell Res. 192: 511-523.

Keith, C.T. and S.L. Schreiber. 1995. PIK-related kinases: DNA repair, recombination, and cell cycle checkpoints. Science 270: 50-51.

Kharbanda, S., P. Pandey, S. Jin, S. Inoe, A. Bharti, Z. Yuan, R. Welchsel baum, D. Weaver, and D. Kufe. 1997. Functional interaction between DNA-PK and c-Abl in response to DN A damage. Nature 386: 732-735.

Koehler, D.R. and P.C. Hanawalt. 1996. Recruitment of dam- 
aged DNA to the nuclear matrix in hamster cells following ultraviolet irradiation. Nucleic Acids Res. 24: 2877-2884.

Korte, C.C. and L.S. Yasui. 1993. Morphological characterization of the radiation sensitive cell line, xrs-5. Scanning Microsc. 7: 943-951.

Krauth, W. and D. Werner. 1979. Analysis of the most tightly bound proteins in eukaryotic DN A. Biochim. Biophys. Acta 564: $390-401$.

Lai, J.S. and W. Herr. 1992. Ethidium bromide provides a simple tool for identifying genuine DN A-independent protein associations. Proc. Natl. Acad. Sci. 89: 6958-6962.

Lavender, P., L. Vandel, A.J. Bannister, and T. Kouzarides. 1997. The HMG-box transcription factor HBP1 is targeted by the pocket proteins and E1A. Oncogene 14: 2721-2728.

Lieber, M.R., U. Grawunder, X. Wu, and M. Yaneva. 1997. Tying loose ends: Roles of Ku and DN A-dependent protein kinase in the repair of double-strand breaks. Curr. Opin. Genet. Dev. 7: 99-104.

Nehls, P., T. Keck, R. Greferath, E. Spiess, T. Glaser, K. Rothbarth, H. Stammer, and D. Werner. 1998. cDNA cloning, recombinant expression and characterization of polypeptides with exceptional DNA affinity. Nucleic Acids Res. 26: 1160-1166.

N elson, W.G., K.J. Pienta, E.R. Barrack, and D.S. Coffey. 1986. The role of nuclear matrix in the organization and function of DN A. Annu. Rev. Biophys. Biophys. Chem. 115: 457-465.

N euer, B. and D. Werner. 1985. Screening of isolated DN A for sequences rel eased from anchorage sites in nucl ear matrix. J. Mol. Biol. 181: 15-25.

Neuer-Nitsche, B., X. Lu, and D. Werner. 1988. Functional role of a highly repetitive DNA sequence in anchorage of the mouse genome. Nucleic Acids Res. 16: 8351-8360.

Pfutz, M., O. Gileadi, and D. Werner. 1992. Identification of human satel lite DN A-sequences associated with chemically resistant nonhistone polypeptide adducts. Chromosoma 101: 609-617.

Roth, D.B., T. Lindahl, and M. Gellert. 1995. How to make ends meet. Curr. Biol. 5: 496-499.

Sambrook, J., E.F. Fritsch, and T. Maniatis. 1989. Isolation of total RNA from mammalian cells. In Molecular cloning. A laboratory manual, pp.7.6-7.11. Cold Spring Harbor Laboratory Press, Cold Spring Harbor, NY.

Shieh, S-Y., M. Ikeda, Y. Taya, and C. Prives. 1997. DN A damage-induced phosphorylation of p53 alleviates inhibition by MDM 2. Cell 91: 325-334.

Shengfang, J., S. Kharbanda, B. Mayer, D. Kufe, and D.T. Weaver. 1997. Binding of $\mathrm{Ku}$ and $\mathrm{C}-\mathrm{Abl}$ at the kinase homolgy region of DNA-dependent protein kinase catalytic subunit. J. Biol. Chem. 272: 24763-24766.

Smith, G.C.M., N. Divecha, N.D. Lakin, and S.P. Jackson. 1998. The DNA-dependent protein kinase and related proteins. Biochem. Soc. Symp. 64: 87-100.

Suwa, A., M. Hirakata, Y. Takeda, S.A. Jesch, T. Mimori, and J.A. Hardin. 1994. DNA-dependent protein kinase (Ku protein-p350 complex) assembles on double-stranded DNA. Proc. Natl. Acad. Sci. 91: 6904-6908.

Tsukamoto, Y., J. Kato, and H. Ikeda. 1997. Silencing factors participate in DNA repair and recombination in Saccharomyces cerevisiae. Nature 388: 900-903.

Verheijen, R., W. Van Venrooij, and F. Ramaekers. 1988. The nuclear matrix: Structure and composition. J. Cell Sci. 90: 11-36.

Watanabe, F., H. Shirakawa, M. Yoshida, K. Tsukada, and H. Teraoka. 1994. Stimulation of DNA-dependent protein kinase activity by high mobility group protein- 1 and protein- 2 . Biochem. Biophys. Res. Com. 202: 736-742.
Werner, D. and B. N euer-N itsche. 1989. Site specific location of covalent DNA-polypeptide complexes in the chicken genome. Nucleic Acids Res. 17: 6005-6015.

Yaneva, M., T. Kowalewski, and M.R. Lieber. 1997. Interaction of DNA-dependent protein kinase with DNA and with $\mathrm{Ku}$ : Biochemical and atomic-force microscopy studies. EMBO J. 16: 5098-5112.

Yasui, L.S., L. Ling-Indeck, B. Johnson-Wint, T. Fink, and D. $\mathrm{M}$ olsen. 1991. Changes in the nuclear structure in the radiation-sensitive $\mathrm{CHO}$ mutant cell, xrs-5. Radiat. Res. 127: 269-277.

Yasui, L.S., T.J. Fink, and A.M. Enrique. 1994. N uclear scaffold organization in the $X$-ray sensitive $C$ hinese hamster mutant cell line, xrs-5. Int. J. Radiat. Biol. 65: 185-192. 


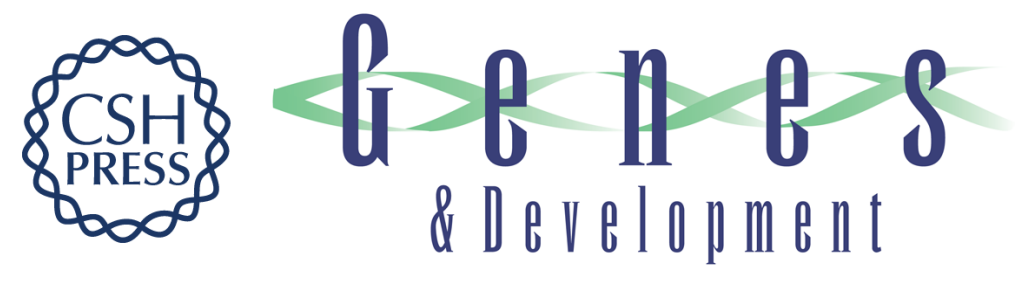

\section{DNA end-independent activation of DNA-PK mediated via association with the DNA-binding protein C1D}

Ugur Yavuzer, Graeme C.M. Smith, Tonya Bliss, et al.

Genes Dev. 1998, 12:

Access the most recent version at doi:10.1101/gad.12.14.2188

$\begin{array}{ll}\text { References } & \begin{array}{l}\text { This article cites } 46 \text { articles, } 11 \text { of which can be accessed free at: } \\ \text { http://genesdev.cshlp.org/content/12/14/2188.full.html\#ref-list-1 }\end{array}\end{array}$

License

Email Alerting Receive free email alerts when new articles cite this article - sign up in the box at the top Service right corner of the article or click here.

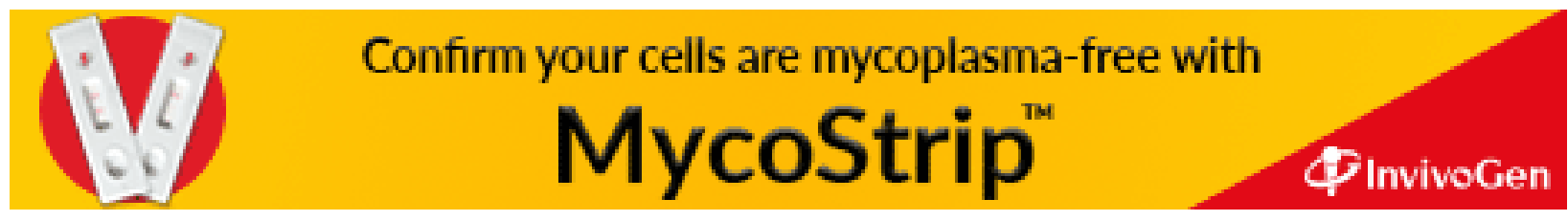

